OPEN ACCESS

Edited by:

Zhiwei Xu,

Nanjing University, China

Reviewed by:

Ruijie Lu,

Beiijng Normal University, China Bernd Wünnemann,

Southwest Jiaotong University, China

${ }^{*}$ Correspondence:

Chongyi $E$

echongyi@163.com

Specialty section:

This article was submitted to

Quaternary Science, Geomorphology

and Paleoenvironment,

a section of the journal

Frontiers in Earth Science

Received: 10 December 2021

Accepted: 17 January 2022

Published: 10 February 2022

Citation:

Xu C, E C, Shi Y, Zhang J, Sun M. Zhang $Z$ and Zeng $Y$ (2022) Holocene Aeolian Activity Recorded by Mountain Paleosols, Gonghe Basin, Northeast

Qinghai-Tibet Plateau.

Front. Earth Sci. 10:832993

doi: 10.3389/feart.2022.832993

\section{Holocene Aeolian Activity Recorded by Mountain Paleosols, Gonghe Basin, Northeast Qinghai-Tibet Plateau}

\author{
Chunxia $X u^{1,2}$, Chongyi $E^{1,2,3 *}$, Yunkun Shi ${ }^{1,2}$, Jing Zhang ${ }^{1,2}$, Manping Sun ${ }^{1,2}$, \\ Zhaokang Zhang ${ }^{1,2}$ and Yongxin Zeng ${ }^{1,2}$
}

${ }^{1}$ Key Laboratory of Tibetan Plateau Land Surface Processes and Ecological Conservation (Ministry of Education), Qinghai Normal University, Xining, China, ${ }^{2}$ Qinghai Province Key Laboratory of Physical Geography and Environmental Process, College of Geographical Science, Qinghai Normal University, Xining, China, ${ }^{3}$ Academy of Plateau Science and Sustainability, People's Government of Qinghai Province and Beijing Normal University, Xining, China

The Gonghe Basin (GHB) on the northeastern Qinghai-Tibet Plateau (NE-QTP) is sensitive to climatic change due to the interplay of the Asian summer monsoon and the westerlies. Extensive aeolian sediments in the basin represent important archives of regional environmental evolution. However, the paleosol development timing is still not clear because of limited number of optically stimulated luminescence (OSL) sampling and dating, which restricts our understanding of past aeolian activities during the Holocene in GHB. In this study, a loess-paleosol section, Najiao (NJ), from the southeastern margin of GHB was investigated. Eighteen OSL samples were obtained from the $400-\mathrm{cm}$ section in order to construct a high-resolution chronological framework. Paleoenvironmental proxies including grain size distribution (GS), magnetic susceptibility (MS), total organic carbon (TOC), and geochemical elements were measured to reconstruct the Holocene aeolian activity. Results show a successive accumulation from Early to Middle Holocene at $\mathrm{NJ}$ section, but a c. 3 ka sedimentary hiatus is found between c. 5 and $1.5 \mathrm{ka}$. Paleosol ages are constrained by high-resolution OSL ages which are from c. 7-5 ka. Consistent with previous studies, strong aeolian activities occurred in GHB during the Early Holocene (c. 13-9 ka), indicating dry climate conditions. Initiation of pedogenesis was at c. $9 \mathrm{ka}$, and the intensified soil development and lowest aeolian activity were between c. 7 and $5 \mathrm{ka}$. The increased sand content after c. $1.5 \mathrm{ka}$ indicates enhanced human activities in the interior of GHB in the Late Holocene.

Keywords: aeolian activity, high resolution, OSL dating, holocene climate, human activities

\section{INTRODUCTION}

The arid/semi-arid northeastern Qinghai-Tibet Plateau (NE-QTP) is particularly sensitive to climatic change as it is under the interplay between the Asian summer monsoon and the westerlies (An et al., 2012; Chen et al., 2016). Sediments, tree rings, and ice cores are important archives of regional environmental and climatic change on the NE-QTP (An et al., 2012; Chen et al., 2016). Aeolian deposits are widespread on the arid NE-QTP, and taken as an important proxy for reconstructing paleoclimatic change, which is well-studied since the 1980s (Xu, 1987; Liu et al., 2012; Qiang et al., 2013; Sun et al., 2014; Hu et al., 2015; Qiang et al., 2016; Liu et al., 2017; Qin et al., 2017; Li et al., 2020). Generally, aeolian activity was stronger and accumulation rates were higher under the 
dry-cold climate during the Late Glacial to Early Holocene, while dune activity was weaker in the more humid Mid-Holocene, and intensified again in the Late Holocene (Stauch et al., 2016; Chen et al., 2020). It has been reported that natural factor was the dominant control on millennial-scale dust storm activity during most of the Holocene, but an upturn in dust storms since c. 2 cal ka BP has been linked with increasing human populations/ intensifying human disturbance in dust source regions of northern China (Chen et al., 2021). Thus, aeolian activity is not only related to climate change, but also to human activity, on different timescales.

Aeolian deposits contain occasional paleosols that were formed when dunes were stabilized due to vegetation development. Published optically stimulated luminescence (OSL) ages for paleosol formation show great variation between basins, and even for different parts of the same basin, due to its limited occurrence (Chen et al., 2020) and moisture effects of local terrain (Qiang et al., 2013). However, few studies have considered the role of soil development mode on paleosol age, which limits understanding of paleoenvironments. The ideal soil development mode for reconstructing paleoenvironmental variations is "aeolian dust aggradation", i.e., continuous accumulation of aeolian sand or dust over at least the millennial scale in either dry-cold or warm-wet periods. In such cases, paleosol development is simultaneous with dust input and paleosol OSL ages directly reflect the timing of humidity (Ee et al., 2018; Zhang et al., 2020). However, at the millennial scale, aeolian sedimentation on the NE-QTP is not continuous (Chongyi et al., 2018; Zhang et al., 2018; Chongyi et al., 2019; Yan et al., 2019; Zhang et al., 2020). During periods of warm and humid climate, dust input reduces and strong pedogenesis may occur; the mode of soil development comprises (in-situ) chemical weathering of aeolian-or other-parent material (E et al., 2018b; Zhang et al., 2020). Due to the predominately aeolian parent material, paleosol OSL ages indicate the timing of dust or sand deposition rather than soil formation. Thus, quartz OSL ages can be taken to indicate an upper limit to soil formation (Miao et al., 2016; Zhang et al., 2020), and the duration of mountain soil development can be effectively constrained by high-resolution OSL ages of deposits at different depths. In addition, high-resolution OSL sampling is an effective means of verifying the continuity of aeolian sedimentation and underpins millennial-scale paleoenvironmental reconstruction during the Holocene ( $\mathrm{Lu}$ et al., 2006).

The Gonghe Basin (GHB) is the largest intramontane basin on the NE-QTP (Stauch et al., 2016) and its location in the arid/semiarid transition zone makes it sensitive to climate change and environmental evolution. The prevailing westerly wind and high vegetation coverage of mountain areas in the southwestern basin provide suitable trapping and preservation conditions of dust and there are thick aeolian deposits. In this study, high-resolution OSL dating of a mountain sediment profile at Najiao (NJ) in the southwestern GHB, combined with analysis of grain size (GS), low frequency magnetic susceptibility (MS), total organic carbon (TOC), and geochemical elements, is used to constrain the timing of paleosol development and reconstruct Holocene aeolian activity. The findings are used to discuss the forcing mechanisms of aeolian activity in the context of regional ecological and climatic change.

\section{Regional Setting}

GHB (average elevation 3,000 $\mathrm{m}$ asl) is bounded by mountains, with Xiqing Mountain of the Qinling system to the east, the Heka, Ela, Wahong Mountains of the Kunlun system to the south and southeast, Qinghai South Mountain (and Qinghai Lake) to the north, and the Waligong, and Riyue Mountains to the northeast (Figure 1A) (Liu et al., 2013a; Liu et al., 2013b). The basin trends NW-SE, with an area of $13,800 \mathrm{~km}^{2}$, a width of $30-90 \mathrm{~km}$, and a length of approximately $210 \mathrm{~km}$ (Liu et al., 2013a; Liu et al., $2013 \mathrm{~b})$. The region is characterized by a cold and dry alpine and arid/semi-arid climate, with an annual evaporation of $528-1937 \mathrm{~mm}$, a temperature and precipitation of $1.0-5.2^{\circ} \mathrm{C}$ and 311.1-402.1 $\mathrm{mm}$, with precipitation accounting for c. $80 \%$ in summer (Liu et al., 2020). The natural vegetation shows strong altitudinal zonation. Below $3,000 \mathrm{~m}$, vegetation is mainly characterized by desert and desert steppe, with some mosaic meadows in lowland areas. Around $3,200 \mathrm{~m}$, the vegetation consists of typical steppe adjacent to diluvial piedmont fans. Over $3,600 \mathrm{~m}$, subalpine meadows dominate the community along the mountainside in the eastern GHB (Qiang et al., 2016). The main areas of desert comprise Muge Sands and Talatan Plain, with mobile, semi-fixed, and fixed sand dunes.

\section{MATERIALS AND METHODS}

\section{Lithology and Sample Collection}

The NJ section $\left(35^{\circ} 40^{\prime} 23.15^{\prime \prime} \mathrm{N}, 101^{\circ} 5^{\prime} 49.04^{\prime \prime} \mathrm{E}, 3,629 \mathrm{~m}\right.$ altitude) (Figures 1A,B) is in the eastern Muge Sand, in the southwestern GHB. Surface vegetation is the subalpine meadow, with an outcrop thickness of $4 \mathrm{~m}$. Based on lithology, the section can be divided into six layers: 0-35 cm, modern soil; $35-185 \mathrm{~cm}$, weak paleosol, of which $10-60 \mathrm{~cm}$ contains white pseudomycelium; $185-235 \mathrm{~cm}$, paleosol; $235-385 \mathrm{~cm}$, loess; $385-395 \mathrm{~cm}$, weak paleosol; 395-400 cm, loess. Total 18 OSL samples were collected at $10 \mathrm{~cm}$ intervals in/close to the paleosol layer and at $40 \mathrm{~cm}$ intervals elsewhere. Proxy samples-for GS, TOC, MS, and geochemical elements analysis-were collected continuously at $5 \mathrm{~cm}$ intervals, giving a total of 108 samples.

\section{Proxy Analyses}

A total of 108 samples have been used for measurements of GS, MS and TOC. Composition of geochemical elements was collected from 64 samples to calculate the rubidium/strontium ratio $(\mathrm{Rb} / \mathrm{Sr})$ that reflects the leaching degree of aeolian sediment in the process of weathering and pedogenesis (Nesbitt and Young, 1989; Chen et al., 1999). The GS distribution taken as an indicator of the intensity of aeolian activity was measured by a Malvern 2000 laser particle size analyzer, using the method described by Lu and An (1997). After removing carbonates, the TOC content indicating vegetation coverage and biomass was performed on an Elementar Vario TOC Cube analyzer (Gasse et al., 1991). Geochemical elements were carried out using the wavelength 


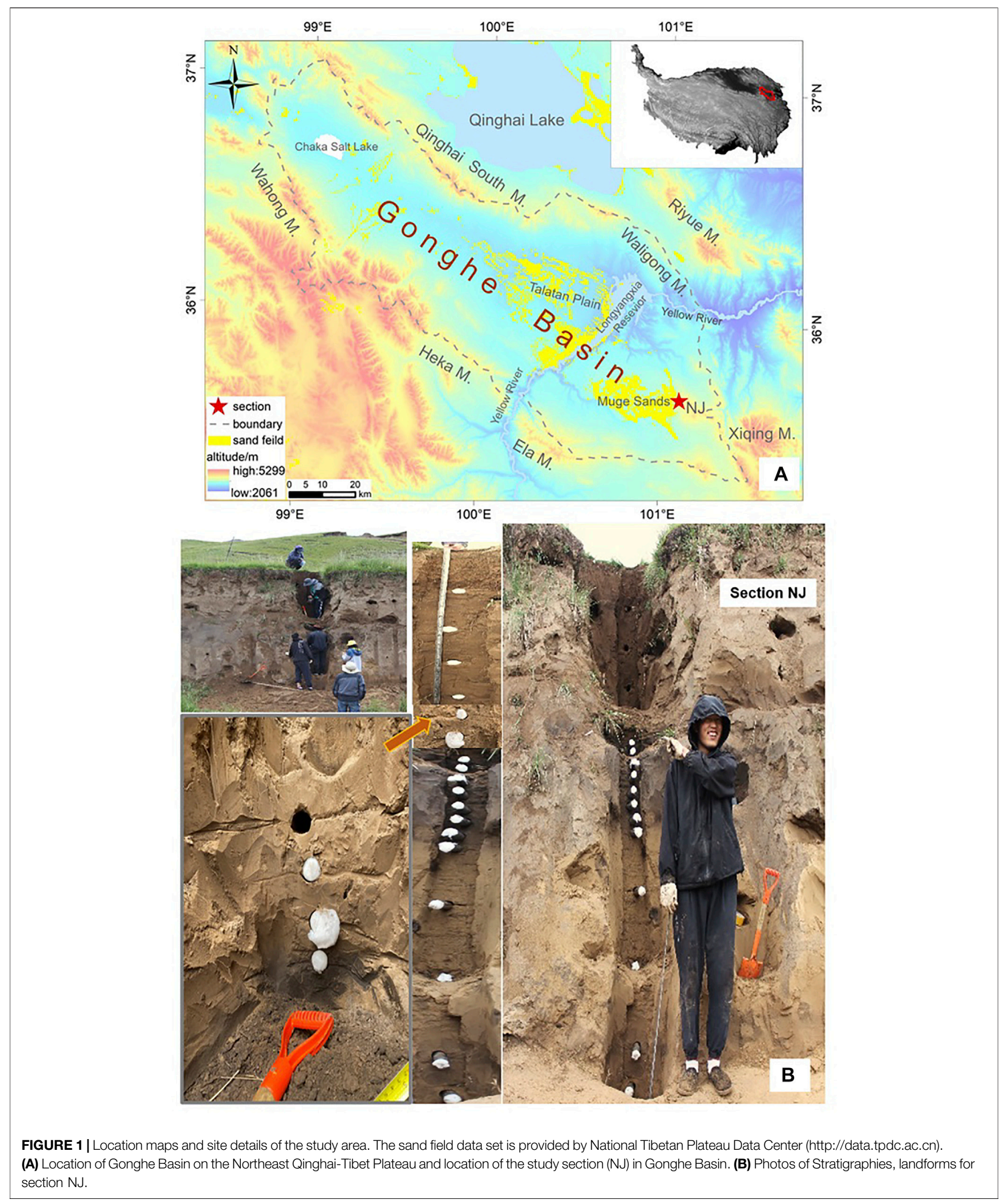


TABLE 1 | OSL dating results for section NJ, Gonghe Basin, NE-QTP.

\begin{tabular}{|c|c|c|c|c|c|c|c|c|c|}
\hline Sample & Depth & ${ }^{40} \mathrm{~K}$ & ${ }^{238} \mathrm{U}$ & ${ }^{232} \mathrm{Th}$ & $\begin{array}{l}\text { Water } \\
\text { content }\end{array}$ & $\mathbf{D}_{e}$ & $\begin{array}{l}\text { Dose } \\
\text { rate }\end{array}$ & Number & Age \\
\hline No. & $/ \mathrm{cm}$ & $1 \%$ & /ppm & /ppm & $1 \%$ & /Gy & /(Gy/ka) & /discs & $/ \mathbf{k a}$ \\
\hline NJ1 & 40 & $1.61 \pm 0.04$ & $1.36 \pm 0.3$ & $7.68 \pm 0.6$ & $10 \pm 5$ & $1.29 \pm 0.07$ & $3.22 \pm 0.14$ & 18 & $0.4 \pm 0.03$ \\
\hline NJ2 & 80 & $1.70 \pm 0.04$ & $1.40 \pm 0.3$ & $8.02 \pm 0.6$ & $10 \pm 5$ & $2.55 \pm 0.15$ & $2.80 \pm 0.13$ & 18 & $1.0 \pm 0.07$ \\
\hline NJ3 & 120 & $1.70 \pm 0.04$ & $1.31 \pm 0.3$ & $7.13 \pm 0.6$ & $10 \pm 5$ & $3.66 \pm 0.18$ & $2.70 \pm 0.12$ & 18 & $1.4 \pm 0.1$ \\
\hline NJ4 & 160 & $1.72 \pm 0.04$ & $1.31 \pm 0.3$ & $7.49 \pm 0.6$ & $10 \pm 5$ & $4.89 \pm 0.29$ & $2.72 \pm 0.12$ & 18 & $1.9 \pm 0.1$ \\
\hline NJ5 & 170 & $1.79 \pm 0.04$ & $1.90 \pm 0.3$ & $9.76 \pm 0.6$ & $10 \pm 5$ & $3.85 \pm 0.51$ & $3.07 \pm 0.14$ & 16 & $1.3 \pm 0.2$ \\
\hline NJ6 & 180 & $1.84 \pm 0.04$ & $2.03 \pm 0.3$ & $10.64 \pm 0.7$ & $10 \pm 5$ & $4.45 \pm 0.58$ & $3.2 \pm 0.15$ & 16 & $1.4 \pm 0.2$ \\
\hline NJ7 & 190 & $1.88 \pm 0.04$ & $1.46 \pm 0.3$ & $9.38 \pm 0.6$ & $10 \pm 5$ & $15.53 \pm 0.40$ & $2.88 \pm 0.12$ & 18 & $5.4 \pm 0.3$ \\
\hline NJ8 & 200 & $1.79 \pm 0.04$ & $1.49 \pm 0.3$ & $9.53 \pm 0.6$ & $10 \pm 5$ & $20.85 \pm 0.62$ & $2.81 \pm 0.12$ & 18 & $7.4 \pm 0.4$ \\
\hline NJ9 & 210 & $1.71 \pm 0.04$ & $1.36 \pm 0.3$ & $9.89 \pm 0.6$ & $10 \pm 5$ & $23.46 \pm 0.44$ & $2.74 \pm 0.12$ & 18 & $8.3 \pm 0.4$ \\
\hline NJ10 & 220 & $1.76 \pm 0.04$ & $1.41 \pm 0.3$ & $8.96 \pm 0.6$ & $10 \pm 5$ & $25.85 \pm 0.46$ & $2.72 \pm 0.12$ & 18 & $9.5 \pm 0.5$ \\
\hline NJ11 & 230 & $1.77 \pm 0.04$ & $1.65 \pm 0.3$ & $9.16 \pm 0.6$ & $10 \pm 5$ & $28.35 \pm 1.14$ & $2.97 \pm 0.13$ & 18 & $9.5 \pm 0.7$ \\
\hline NJ12 & 240 & $1.74 \pm 0.04$ & $1.50 \pm 0.3$ & $9.40 \pm 0.6$ & $10 \pm 5$ & $29.44 \pm 1.12$ & $2.75 \pm 0.12$ & 18 & $10.7 \pm 0.7$ \\
\hline NJ13 & 250 & $1.64 \pm 0.04$ & $1.38 \pm 0.3$ & $7.41 \pm 0.6$ & $10 \pm 5$ & $28.96 \pm 1.99$ & $2.50 \pm 0.11$ & 18 & $11.6 \pm 1.0$ \\
\hline NJ14 & 260 & $1.60 \pm 0.04$ & $1.38 \pm 0.3$ & $7.73 \pm 0.6$ & $10 \pm 5$ & $32.24 \pm 1.72$ & $2.48 \pm 0.11$ & 18 & $13.0 \pm 0.9$ \\
\hline NJ15 & 300 & $1.68 \pm 0.04$ & $1.49 \pm 0.3$ & $8.35 \pm 0.6$ & $10 \pm 5$ & $34.26 \pm 1.43$ & $3.00 \pm 0.14$ & 18 & $12.0 \pm 0.8$ \\
\hline NJ16 & 340 & $1.77 \pm 0.04$ & $1.70 \pm 0.3$ & $9.69 \pm 0.6$ & $10 \pm 5$ & $35.19 \pm 1.45$ & $2.94 \pm 0.14$ & 18 & $12.6 \pm 0.8$ \\
\hline NJ17 & 380 & $1.75 \pm 0.04$ & $1.79 \pm 0.3$ & $10.39 \pm 0.6$ & $10 \pm 5$ & $31.07 \pm 0.86$ & $2.98 \pm 0.14$ & 18 & $11.0 \pm 0.6$ \\
\hline NJ18 & 400 & $1.73 \pm 0.04$ & $1.70 \pm 0.3$ & $9.42 \pm 0.6$ & $10 \pm 5$ & $33.55 \pm 1.67$ & $2.87 \pm 0.13$ & 18 & $12.3 \pm 0.9$ \\
\hline
\end{tabular}

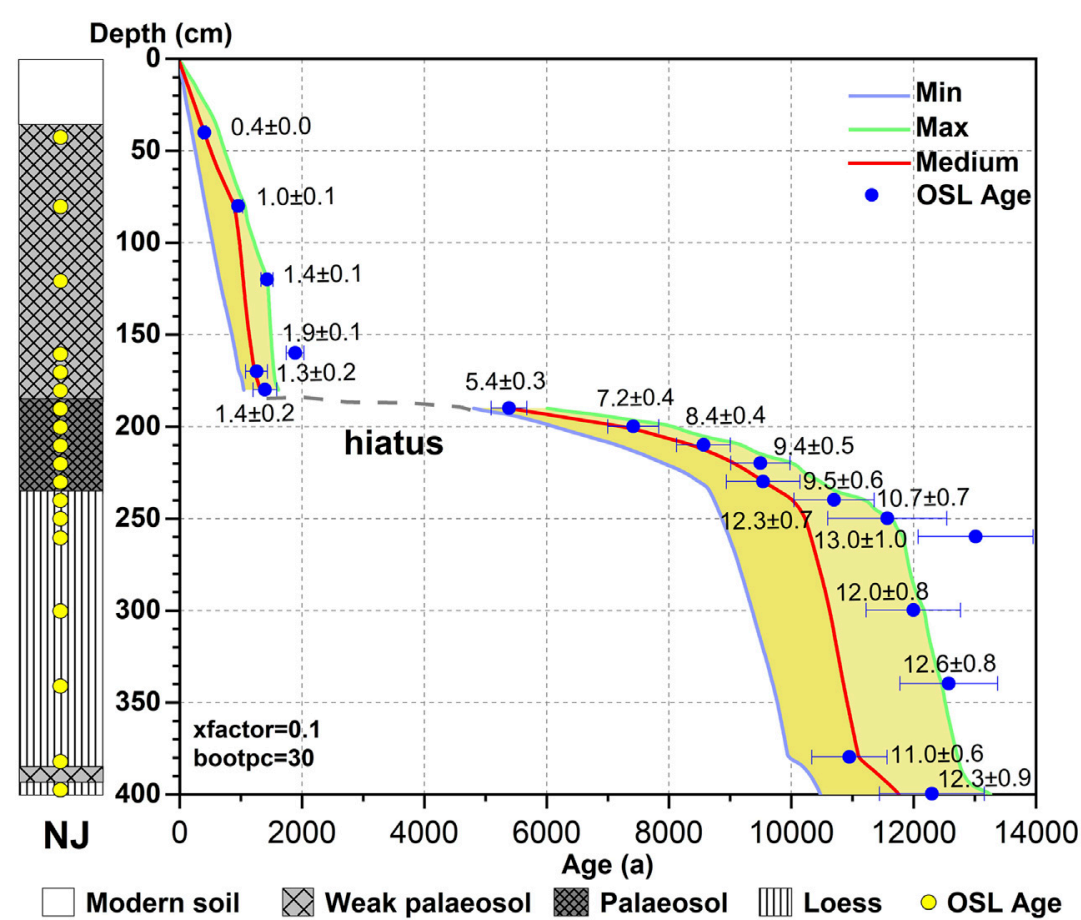

FIGURE 2 | Age-depth relationship for the NJ section based on the Undatable model (Lougheed and Obrochta, 2019).

dispersion type of X-ray fluorescence spectrometer following a routine pretreatment protocol (Liu et al., 2013a). MS was measured by a Bartington MS2 meter after drying the samples below $40^{\circ} \mathrm{C}$.
OSL Dating

The quartz fraction of $63-90 \mu \mathrm{m}$ was extracted for equivalent dose $\left(\mathrm{D}_{e}\right)$ determination. Extracted quartz was checked for purity using infrared stimulated luminescence (IRSL) measurements 

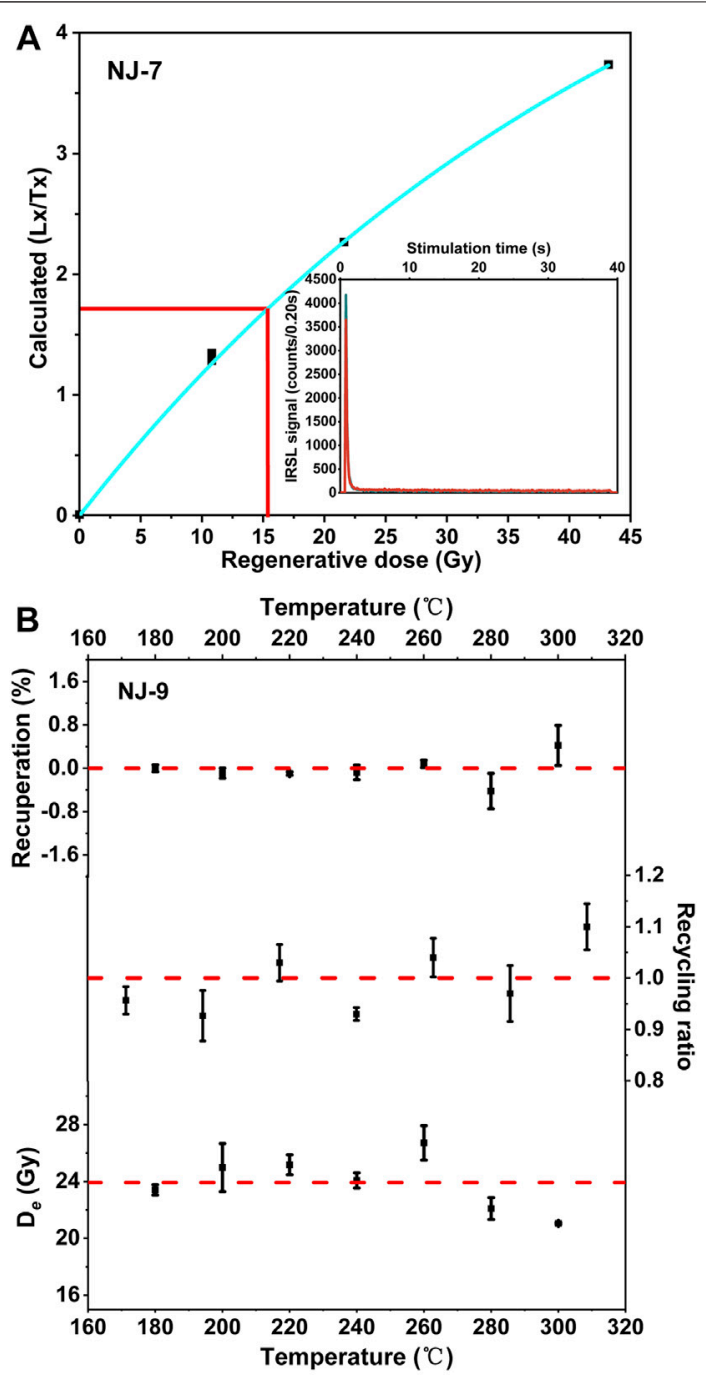

C

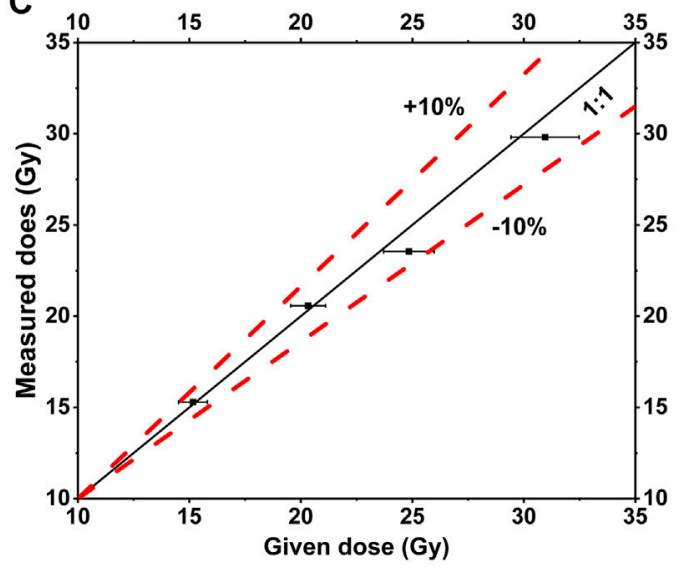

FIGURE 3 |OSL characteristics for samples, NJ section. (A) Growth and decay (inset) curves for sample NJ-7. (B) Preheat plateau tests $\left(D_{e}\right)$ at sample NJ-9 showing a plateau between 180 and $300^{\circ} \mathrm{C}$. (C) Dose recovery test. Given doses versus measured doses for four randomly selected samples. The solid black line is the slope of unity, where the ratio is $100 \%$, and the two red dashed lines indicate 10\% above and below the line. Error bars represent one standard error.
(Duller, 2003). $\mathrm{D}_{e}$ was determined by the single aliquot regenerative (SAR) protocol on a Risø TL/OSL-DA-20-C/D reader (Murray and Wintle, 2000; Wintle and Murray, 2006). For $\mathrm{D}_{e}$ calculations, the signal was derived from the first $0.16 \mathrm{~s}$ of stimulation and an early background (0.16-0.32 s) to minimize the influence of slow and medium components (Cunningham and Wallinga, 2010). $\mathrm{D}_{e}$ rejection criteria were restricted by two test measurements (e.g., $0.9<\mathrm{R} 5 / \mathrm{R} 1<1.1$, and $\mathrm{R} 4 / \mathrm{N}<5 \%$ ). Average $\mathrm{D}_{e}$ was calculated based on the results of 16-18 aliquots.

The concentrations of uranium (U), thorium (Th) and potassium $(\mathrm{K})$ were measured by inductively coupled plasma mass spectrometry for calculating the environmental dose rate. Then the concentrations of $\mathrm{U}$, Th and $\mathrm{K}$ were converted into infinite matrix dry dose rates using the conversion factors of Guérin et al. (2012). The cosmic ray contribution was from Prescott and Hutton (1994). Due to the modern mountain climate is relatively humid, water content was estimated as $10 \pm 5 \%$. Detailed dating information including radionuclide concentrations, dose rates, equivalent doses and age results are summarized in Table 1.

\section{Age-Depth Model}

The age-depth relationship was established in section NJ using the Undatable model to construct the chronological framework and verify continuity of the aeolian sediment accumulation on millenial scale (Figure 2). Undatable model is a rapid, deterministic age-depth modeling routine for geological sequences, using Matlab software and programming practices (Lougheed and Obrochta, 2019). For the NJ section, model parameters xfactor $=0.1$ and bootpc $=30$ were used.

\section{RESULTS}

\section{Quartz Luminescence Characteristics}

The quartz OSL signal of sample NJ-7 rapidly decreased to background in the first $2 \mathrm{~s}$, indicating a fast component (Figure 3A). Preheat plateau tests were carried out on NJ-9 to select an appropriate preheating regime (Figure 3B). There is an apparent plateau between $180^{\circ} \mathrm{C}$ and $240^{\circ} \mathrm{C}$. All of the recycling ratios are between 0.9 and 1.1 under different preheat temperature, and all recuperations are smaller than $5 \%$. Consequently, a preheat temperature of $240^{\circ} \mathrm{C}$ and a cut-heat temperature of $200^{\circ} \mathrm{C}$ was selected to determine quartz De for all samples. Four randomly selected samples were chosen for dose recovery test, and all ratios lie within $10 \%$ of the slope of unity, indicating well dose recoveries (Figure 3C).

\section{Dating Results}

Within one standard error, OSL ages are generally grown with the increase of sampling depth, except for one age inversions in upper weak paleosol with an age of $1.9 \pm 0.1 \mathrm{ka}$ at the depth of $1.5 \mathrm{~m}$. The 2-m deep upper weak paleosol layer was deposited in the last c. $1.5 \mathrm{ka}$. The loess age is concentrated from $12.3 \pm 0.9 \mathrm{ka}$ to $9.5 \pm$ $0.6 \mathrm{ka}$. The apparent paleosol age is from $9.4 \pm 0.5 \mathrm{ka}$ to $5.4 \pm$ $0.3 \mathrm{ka}$. 


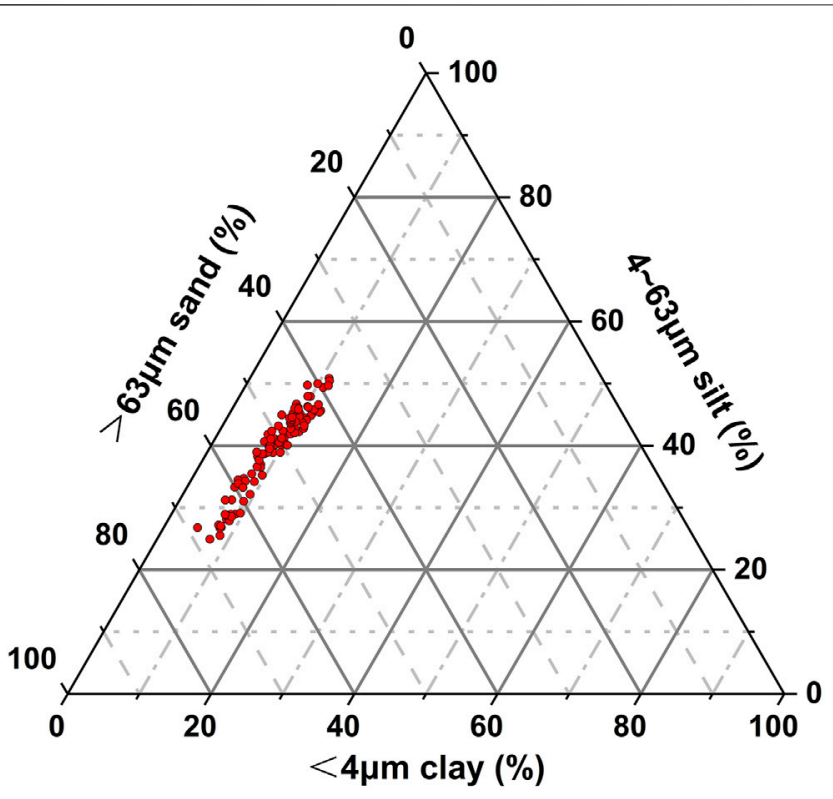

FIGURE 4 | Ternary diagram showing grain size components for samples from the NJ section.

The resulting age-depth curve (Figure 2) shows a continuous deposition from the Early to Middle Holocene and after $1.5 \mathrm{ka}$. A c. $3 \mathrm{ka}$ hiatus in deposition took place in the Late Holocene (c. $5-1.5 \mathrm{ka}$ ). Similar millennial-scale hiatuses have been identified in other high-resolution OSL dated aeolian sections elsewhere on the NE-QTP (Zhang et al., 2018; E et al., 2019; Yan et al., 2019), indicating ubiquitous discontinuity in aeolian deposits over millennial-scale on the entire Qinghai-Tibet Plateau (QTP).

\section{Proxy Results}

The NJ section mainly comprises sand size sediment $(>63 \mu \mathrm{m})$, ranging from 38.09 to $68.49 \%$ (average 51.31\%) (Figure 4). Comparison of GS distributions between loess, weak paleosol, and paleosol samples (Figure 5) shows they are mostly unimodal grain size distribution with overlapping peaks, indicating they have a similar/single provenance and the material source has been stable over time. According to the prevailing wind direction in $\mathrm{GHB}$ is northwest, the desert in GHB should be the potential material source.

In the NJ section, MS varies from 23.4 to $65.8 \times 10^{-8} \mathrm{~m}^{3} / \mathrm{kg}$ (average $35.7 \times 10^{-8} \mathrm{~m}^{3} / \mathrm{kg}$ ), with the highest value in paleosol and lowest in loess (Figure 6). But the MS in upper sandy weak paleosol is slightly higher than the lower loess. TOC varies from 1.05 to $4.5 \%$ (average $2.13 \%$ ), with the highest proportion in modern soil with upper depth of $25 \mathrm{~cm}$ which is significantly affected by surface litter layer and root matter input (Figure 6). TOC in paleosol is much higher than loess and weak paleosol, but lowest in loess stratum. $\mathrm{Rb} / \mathrm{Sr}$ ratio varies from 0.37 to 0.62 , with an average of 0.5 . Trend similar to TOC and MS is observed in the $\mathrm{Rb} / \mathrm{Sr}$ ratio, which shows the highest value in paleosol and the lowest in loess (Figure 6).

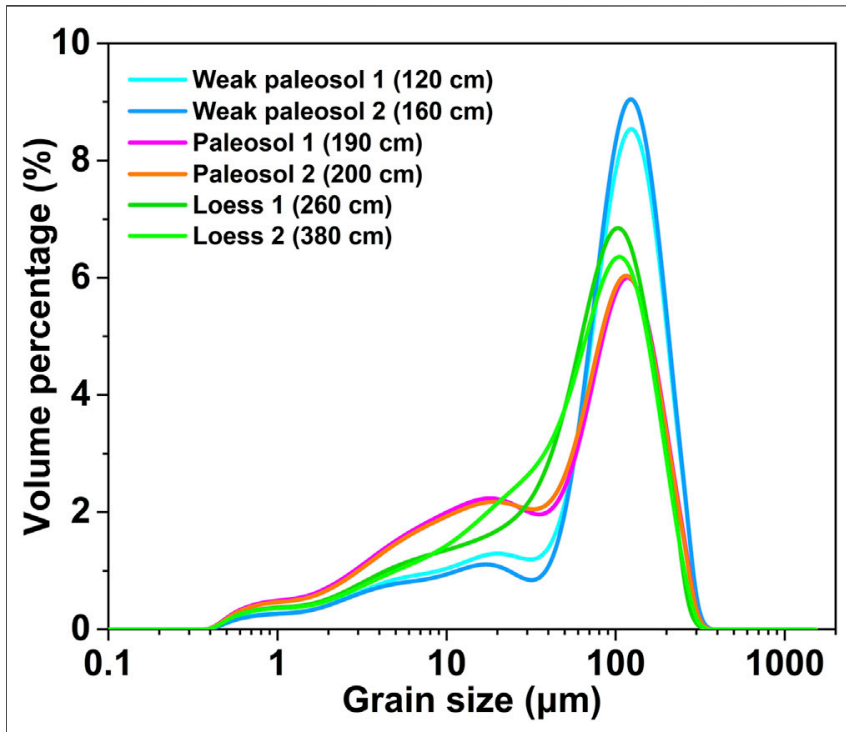

FIGURE 5 | Grain size distribution curves for selected samples from the NJ section.

\section{DISCUSSION}

Timing of Paleosol Development in the GHB

As mentioned above, the accuracy of paleosol OSL ages depends on the soil development mode. The ideal soil development mode for OSL dating is "aeolian dust aggradation", i.e., paleosol development is simultaneous with dust input (E et al., 2018b; Zhang et al., 2020). The high-resolution OSL dating of paleosol layer at NJ section indicates continuous dust deposition on the millennial scale. Thus, the paleosol OSL age falls well within the period of pedogenesis. According to the field observation (Figure 1B), the dark paleosol layer has a thickness of $50 \mathrm{~cm}$ $(185-235 \mathrm{~cm})$ dated from c. 9 ka to c.5 ka, indicating a very low dust accumulation rate during the pedogenic process. Then for obtaining a reliable paleosol age, the high-resolution OSL dating strategy is vital and necessary. The low-resolution OSL sampling strategy is difficult to differ the (in-situ) chemical weathering of previously deposited aeolian parent material or the "aeolian dust aggradation" at least on millennial scale. Therefore, it is not strange that the paleosol ages based on the low-resolution OSL sampling show great variations between basins, and even for different sites in the same basin.

Meanwhile, the environmental proxy indicator of paleoenvironment is equally important to verify the pedogenic intensity. In NJ, the highest MS, TOC, $\mathrm{Rb} / \mathrm{Sr}$ and clay content indicate the strongest pedogenic process occurred during c. 7 to $5 \mathrm{ka}$ in $185-200 \mathrm{~cm}$ (Figure 6). This result is consistent with the lake level highstands in Kuhai (Figure 7F) (Yan et al., 2018) and Qinghai Lake (Liu et al., 2015). Similarly, a high resolution OSL chronology at ND aeolian sand section (E et al., 2019) records the strongest pedogenesis from 6 to $4.5 \mathrm{ka}$ in the neighboring Qinghai Lake area (Figure 7E). The tree ring (Yang et al., 2021) records a wet middle Holocene since 6.7 to $5 \mathrm{ka}$, and the precipitation 


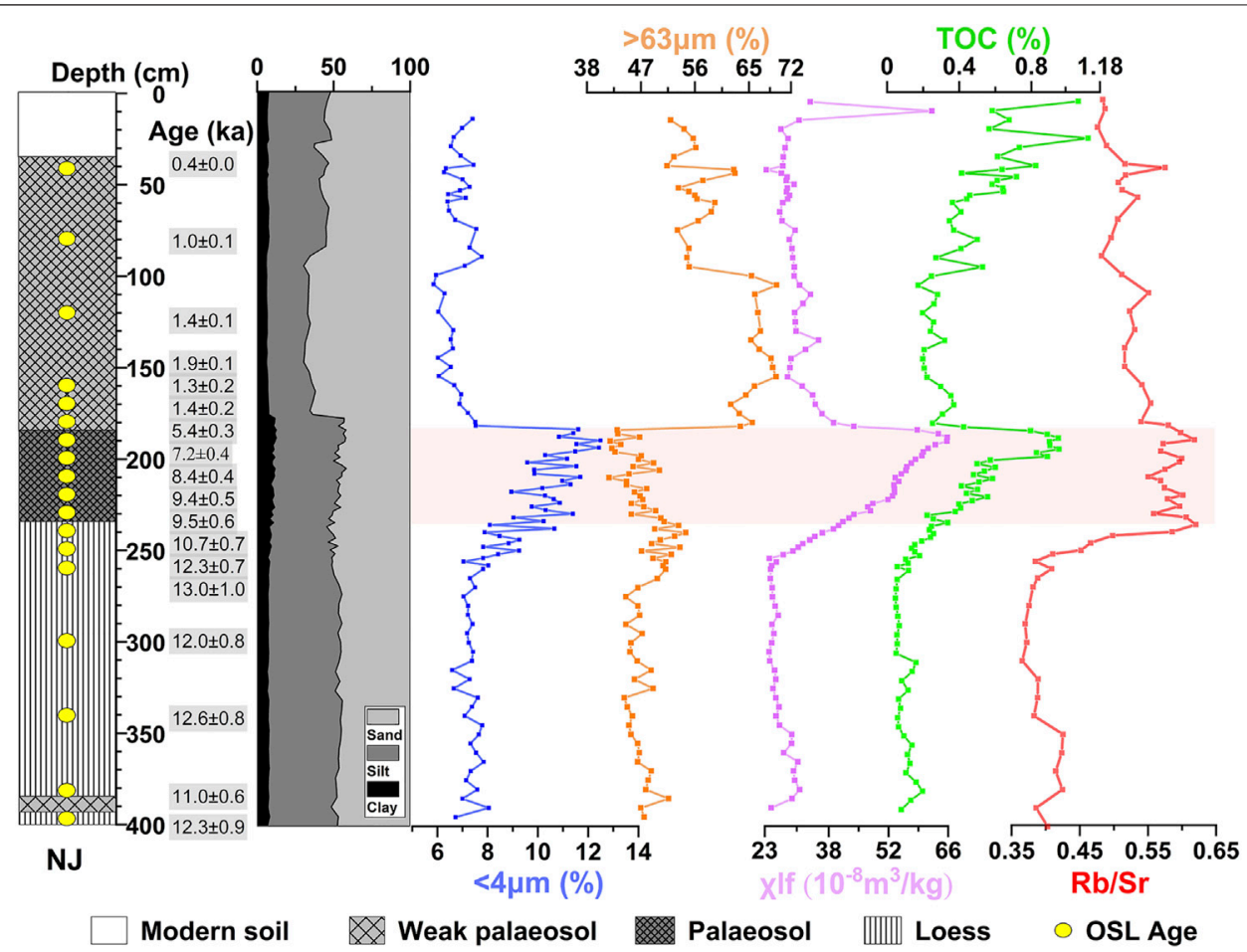

FIGURE 6 | Stratigraphic sequence of the NJ section showing OSL ages and variations in sediment size and various proxy indicators with depth.

decreased remarkably since $4 \mathrm{ka}$ (Figure $7 \mathbf{H})$. Although the deposition of $1.5-5 \mathrm{ka}$ in $\mathrm{NJ}$ is absent, the strongest pedogenic period in GHB is clear in c. 7 to $5 \mathrm{ka}$.

\section{History of Aeolian Activity in the GHB}

The regional aeolian activity in GHB is reconstructed according to the records of different paleoclimate proxy indicators from neighboring sites on the NE-QTP in Figure 7. Three stages can be identified, designed I to III.

Stage I. Late Glacial and Early Holocene (13-9 ka). NJ section lithostratigraphy is characterized by sandy loess with relatively high sand content, reflecting relatively strong and frequent wind. $\mathrm{TOC}$ and $\mathrm{Rb} / \mathrm{Sr}$ are at their lowest in this period, indicating sparse vegetation, weak weathering, and dry climate conditions in general (Figures 7B,C). Aeolian sediment of ND in Qinghai Lake, high salinity of Qinghai Lake and low lake level from Kuhai Lake suggest a strengthened aeolian activity and dry climate condition in NE-QTP (Figures 7E-G) (Zhang et al., 1989; Yan et al., 2018; E et al., 2019). All these results are consistent with the climate change history in QTP (Chen et al., 2020). Overall, climatic conditions in GHB within NE-QTP show a consistent condition and reveal intensified aeolian activity during the early Holocene.

Stage II. Middle Holocene $(9-5 \mathrm{ka})$. NJ section lithostratigraphy shifts to paleosol in this stage. The sand content decreased slightly, but the MS, TOC, clay content and $\mathrm{Rb} / \mathrm{Sr}$ increased significantly. It could indicate increased precipitation, enhanced pedogenesis, high biomass and weakened aeolian activity under relatively stable warm and wet conditions (Figure 6). In the latter part of the period between $\mathrm{c}$. $7-5 \mathrm{ka}$, sand content is at its lowest, TOC and $\mathrm{Rb} / \mathrm{Sr}$ at highest (Figures 7B,C), indicating the strong pedogenesis. These findings are consistent with previous studies in GHB that show the highest moisture levels, and lowest aeolian activity in the Mid-Holocene (Stauch et al., 2016). Similar patterns are observed in other records in the NE-QTP including low mean grain size $(\mathrm{Mz})$ at the ND section (Figure 7E); highest lake level in Kuhai Lake and lowest salinity in Qinghai Lake (Figures 7F,G); and maximal at Qilian Mountain (Yang et al., 2021) between c. $7.6-4 \mathrm{ka}$ (Figure $\mathbf{7 H}$ ). In general, the climatic optimum in the GHB between c. 7-5 ka corresponds with other parts of the NEQTP that record their wettest conditions in the Middle Holocene.

Stage III. Late Holocene (after c. $1.5 \mathrm{ka}$ ). NJ section lithostratigraphy comprises weak paleosol. The sand content in this layer is much higher than the middle to early Holocene paleosol and sandy loess (Figures 6, 7A). It indicates aeolian activities after c. $1.5 \mathrm{ka}$ have been enhanced and are even stronger than early Holocene. Contradictorily, the $\mathrm{Rb} / \mathrm{Sr}$ and TOC are higher than the lower sandy loess, and the MS is slightly higher than the lower sandy loess (Figures 7B-D). All these imply a wetter and better climate condition in the late Holocene than early Holocene. The prevailing wind direction in GHB is northwest, and straight distance from the mountain of NJ section to the Muge sands is less than $10 \mathrm{~km}$ (Figure 1A). Undoubtedly, NJ section recorded enhanced aeolian activities in GHB. Consistently, the stronger aeolian activity after c. $1.5 \mathrm{ka}$ BP was reported in NE-QTP by the summarization of 93 aeolian sand OSL ages from 39 sections (Chen et al., 2016). 


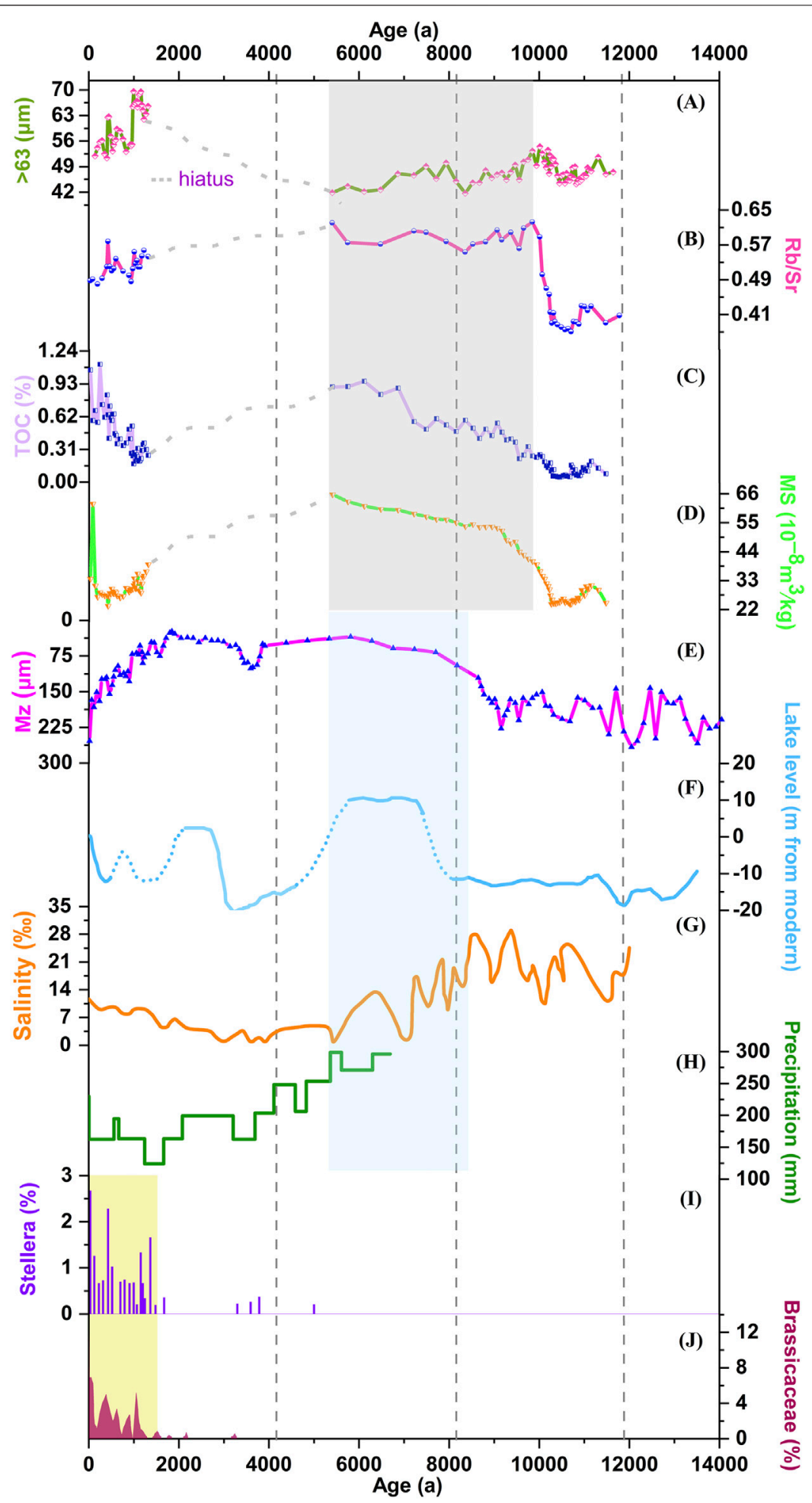

FIGURE 7 | Comparison of proxy indicators for the NJ section with published paleoclimate records for other sites on the Northeast Qinghai-Tibet Plateau (NE-QTP) (ages based on the Undatable model). (A) >63 $\mu \mathrm{m}$ content, NJ section. (B) Rb/Sr, NJ section. (C) Total organic carbon (TOC), NJ section. (D) Low frequency magnetic susceptibility (MS), NJ section. (E) Mean grain size (Mz), ND section, Qinghai Lake (E et al., 2019). (F) Lake level, core KH17, Kuhai Lake (Yan et al., 2018). (G) Salinity, Qinghai Lake (Zhang et al., 1989). (H) Precipitation, tree ring DLH, Qilian Mountains (Yang et al., 2021). (I) Stellera pollen, core GGHA, Gonghe Basin (Liu et al., 2016). (J) Brassicaceae pollen, core GGHA, Gonghe Basin (Huang et al., 2017). 
However, there was no decreasing trend after $1.5 \mathrm{ka} \mathrm{BP}$ in the precipitation reconstruction based on tree rings from Qilian Mountain after $3.5 \mathrm{ka}$ BP (Figure 7H) (Yang et al., 2021). It was inferred that the increased aeolian activity after c.1.5 ka BP is not related to climate change but a consequence of intensified human activity (Zhang et al., 1988; Chen et al., 2016). Pollen from Genggahai Lake in GHB suggests an intensification of human settlement and grazing activity after c. $1.4 \mathrm{ka}$ by high percentages of Stellera and Brassicaceae pollen and Sporormiella spores (Liu et al., 2016; Huang et al., 2017, Huang et al., 2020) (Figures 7I,J). Repeated shifts between nomadic pasture and farmland in the Qinghai Lake area since the late Western Han Dynasty $(2.0-1.8 \mathrm{ka}, 1.9-1.5 \mathrm{ka})$ may promote aeolian activity (Sun et al., 2021; Wei et al., 2021). For broader northern China, increased dust storms since c. $2 \mathrm{ka}$ BP were also closely linked to increasing human populations in the dust source regions of northern China (Chen et al., 2021). In the interior of GHB, the intensity of human activity is much stronger and the ecological resistance is much lower. With the enhancement of human activities in the interior of GHB, sand supply was increased to the mountain soils as parental material. Increased sand contents dilute clay contents and magnetic minerals that produced by pedogenesis, then the MS of weak plaeosol present a lower feature. $\mathrm{Rb} / \mathrm{Sr}$ ratio is less affected by aeolian activity because it reflects the proportionality of the relative contents of two elements (Wang et al., 2020), so $\mathrm{Rb} / \mathrm{Sr}$ ratio reflects pedogenesis more likely, similar with TOC.

Overall, strong aeolian activities in GHB since c. $1.5 \mathrm{ka} \mathrm{BP}$ is closely related to the enhanced human activities than natural variability of climate.

\section{CONCLUSION}

The duration of mountain soil development in GHB was effectively constrained by high-resolution OSL ages from c. $7-5 \mathrm{ka}$. The period of strong pedogenesis is consistent with the warm and wet climatic condition recorded with tree rings and high lake levels in NE-QTP. A successive accumulation at the NJ section was recorded over the millennial scale during the Early to Middle Holocene in GHB, but a c. 3 ka hiatus was found between c. 5 and $1.5 \mathrm{ka}$. The aeolian activities showed a strong aeolian

\section{REFERENCES}

An, Z., Colman, S. M., Zhou, W., Li, X., Brown, E. T., Jull, A. J. T., et al. (2012). Interplay between the Westerlies and Asian Monsoon Recorded in Lake Qinghai Sediments since 32 Ka. Sci. Rep. 2, 619. doi:10.1038/srep00619

Chen, F., Wu, D., Chen, J., Zhou, A., Yu, J., Shen, J., et al. (2016). Holocene Moisture and East Asian Summer Monsoon Evolution in the Northeastern Tibetan Plateau Recorded by Lake Qinghai and its Environs: A Review of Conflicting Proxies. Quat. Sci. Rev. 154, 111-129. doi:10.1016/j.quascirev.2016. 10.021

Chen, F., Zhang, J., Liu, J., Cao, X., Hou, J., Zhu, L., et al. (2020). Climate Change, Vegetation History, and Landscape Responses on the Tibetan Plateau during the Holocene: A Comprehensive Review. Quat. Sci. Rev. 243, 106444. doi:10. 1016/j.quascirev.2020.106444 activity in GHB during Early Holocene (13-9 ka), consistent with the paleoclimatic records on the NE-QTP. Pedogenesis began at c. $9 \mathrm{ka}$, with the most intensive paleosol development, and the lowest aeolian activity in c. 7-5 ka. Weak paleosol development after c. $1.5 \mathrm{ka}$, but increased sand content, imply that human activities were enhanced in the interior of GHB in the Late Holocene.

\section{DATA AVAILABILITY STATEMENT}

The original contributions presented in the study are included in the article/Supplementary Material, further inquiries can be directed to the corresponding author.

\section{AUTHOR CONTRIBUTIONS}

CX performed the OSL dating, proxy data measurement and analysis, and finished writing the manuscript. CE contributed to the conception of the study, organization of the manuscript and manuscript revision. YS, JZ, and MS contributed to the modifications and suggestions. ZZ contributed to the agedepth model. YZ helps in the experimental treatment of OSL dating and proxy analysis.

\section{FUNDING}

The research was funded by the National Natural Science Foundation of China (Grant Nos 42171011, 41761042), the Natural Science Foundation of Qinghai (Grant No. 2021-ZJ-918).

\section{ACKNOWLEDGMENTS}

We thank Ji Xianba, Qiang Peng, Liqian Xie, Fajun Su, Yang Li, Guochuan Xia for helps in the field and thank Barbara Rumsby for editing the manuscript. Special thanks to reviewers and editor Zhiwei $\mathrm{Xu}$ whose constructive suggestions and detailed comments helped to clarify and improve the paper.

Chen, J., Wang, Y. J., Ji, J. F., Chen, Y., and Lu, H. Y. (1999). Rb/Sr Variations and its Climatic Stratigraphical Significance of a Loess-Paleosol Profile from Luochuan, Shanxi Province. Quat. Sci. 19 (4), 350-356.

Chen, S., Liu, J., Wang, X., Zhao, S., Chen, J., Qiang, M., et al. (2021). Holocene Dust Storm Variations over Northern China: Transition from a Natural Forcing to an Anthropogenic Forcing. Sci. Bull. 66, 2516-2527. doi:10.1016/j.scib.2021. 08.008

Chongyi, E., Sohbati, R., Murray, A. S., Buylaert, J.-P., Liu, X., Yang, L., et al. (2018). Hebei Loess Section in the Anyemaqen Mountains, Northeast Tibetan Plateau: A High-Resolution Luminescence Chronology. Boreas 47, 1170-1183. doi:10. 1111/bor.12321

ChongYi, E., Jing, Z., ZongYan, C., YongJuan, S., YaJuan, Z., Ping, L., et al. (2019). High Resolution OSL Dating of Aeolian Activity at Qinghai Lake, Northeast Tibetan Plateau. Catena 183, 104180. doi:10.1016/j.catena.2019. 104180 
Cunningham, A. C., and Wallinga, J. (2010). Selection of Integration Time Intervals for Quartz OSL Decay Curves. Quat. Geochronol. 5, 657-666. doi:10.1016/j.quageo.2010.08.004

Duller, G. A. T. (2003). Distinguishing Quartz and Feldspar in Single Grain Luminescence Measurements. Radiat. Measurements 37, 161-165. doi:10. 1016/S1350-4487(02)00170-1

Ee, C., Zhang, J., Wu, C. Y., Sun, Y. J., Sun, M. P., Yan, W., et al. (2018). Study of Chronology of the Meadow Soil in the Qinghai Lake Basin by Means of Optically Stimulated Luminescence. Acta Pedologica Sinica 55, 1325-1335. doi:10.11766/trxb201801090021

Gasse, F., Arnold, M., Fontes, J. C., Fort, M., Gibert, E., Huc, A., et al. (1991). A 13,000-year Climate Record from Western Tibet. Nature 353, 742-745. doi: $10.1038 / 353742 \mathrm{a} 0$

Guérin, G., Mercier, N., Nathan, R., Adamiec, G., and Lefrais, Y. (2012). On the Use of the Infinite Matrix assumption and Associated Concepts: A Critical Reviewfinite Matrix assumption and Associated Concepts: a Critical Review. Radiat. Measurements 47, 778-785. doi:10.1016/j. radmeas.2012.04.004

Hu, M. J., Yang, A. L., and Zhang, W. L. (2015). Environmental Evolution since the Middle-Late Holocene in the Maqu Plateau Reflected by Constant Element Oxides Content and Ratio. J. Desert Res. 35, 313-321. doi:10.7522/j.issn.1000694X.2015.00002

Huang, X.-z., Liu, S.-s., Dong, G.-h., Qiang, M.-r., Bai, Z.-j., Zhao, Y., et al. (2017). Early Human Impacts on Vegetation on the Northeastern Qinghai-Tibetan Plateau during the Middle to Late Holocene. Prog. Phys. Geogr. Earth Environ. 41, 286-301. doi:10.1177/0309133317703035

Huang, X., Zhang, J., Storozum, M., Liu, S., Gill, J. L., Xiang, L., et al. (2020). Longterm Herbivore Population Dynamics in the Northeastern Qinghai-Tibetan Plateau and its Implications for Early Human Impacts. Rev. Palaeobotany Palynology 275, 104171. doi:10.1016/j.revpalbo.2020.104171

Li, G., Zhang, H., Liu, X., Yang, H., Wang, X., Zhang, X., et al. (2020). Paleoclimatic Changes and Modulation of East Asian Summer Monsoon by High-Latitude Forcing over the Last 130,000 Years as Revealed by Independently Dated LoessPaleosol Sequences on the NE Tibetan Plateau. Quat. Sci. Rev. 237, 106283. doi:10.1016/j.quascirev.2020.106283

Liu, B., Jin, H. L., Sun, Z., Su, Z. Z., and Zhang, C. X. (2013b). Holocene MillennialScale Climatic Change Recorded by Grain Size and Chemical Elements of Peat Deposits in Gonghe Basin, Northeastern Tibetan Plateau. J. Glaciology Geocryology 35, 609-620. doi:10.7522/j.issn.1000-0240.2013.0070

Liu, B., Jin, H. L., Sun, Z., Sun, Z. Z., and Zhang, C. X. (2012). Geochemical Characteristics of Aeolian Deposits in Gonghe Basin, Northeastern QinghaiTibetan Plateau and the Indicating Climatic Changes. Adv. Earth Sci. 27, 788-799.

Liu, B., Jin, H., Sun, L., Su, Z., Zhang, C., and Zhao, S. (2017). History of Moisture Change Derived from Slope Sediments of the Eastern Gonghe Basin (Northeastern Qinghai-Tibetan Plateau) during the Last 17 Ka. Geol. J. 52, 583-593. doi:10.1002/gj.2795

Liu, B., Jin, H., Sun, L., Sun, Z., and Su, Z. (2013a). Winter and Summer Monsoonal Evolution in Northeastern Qinghai-Tibetan Plateau during the Holocene Period. Geochemistry 73, 309-321. doi:10.1016/j.chemer.2013.03.006

Liu, B., Zhao, H., Jin, H., and Chen, F. (2020). Holocene Moisture Variation Recorded by Aeolian Sand-Palaeosol Sequences of the Gonghe Basin, Northeastern Qinghai-Tibetan Plateau, China. Acta Geologica Sinica English Edition 94, 668-681. doi:10.1111/1755-6724.14541

Liu, S. S., Huang, X. Z., Qiang, M. R., Lin, X. R., Bai, Z. J., and Peng, W. (2016). Vegetation and Climate Change during the Mid-late Holocene Reflected by the Pollen Record from Lake Genggahai, Northeastern Tibetan Plateau. Quat. Sci. 36, 247-256. doi:10.11928/j.issn.1001-7410.2016.02.01

Liu, X.-J., Lai, Z., Madsen, D., and Zeng, F. (2015). Last Deglacial and Holocene lake Level Variations of Qinghai Lake, north-eastern Qinghai-Tibetan Plateau. J. Quat. Sci. 30, 245-257. doi:10.1002/jqs.2777

Lougheed, B. C., and Obrochta, S. P. (2019). A Rapid, Deterministic AgeDepth Modeling Routine for Geological Sequences with Inherent Depth Uncertainty. Paleoceanography and Paleoclimatology 34, 122-133. doi:10. 1029/2018PA003457

Lu, H., Stevens, T., Yi, S., and Sun, X. (2006). An Erosional Hiatus in Chinese Loess Sequences Revealed by Closely Spaced Optical Dating. Chin. Sci Bull 51, 2253-2259. doi:10.1007/s11434-006-2097-x
Lu, H. Y., and An, Z. S. (1997). An Experimental Study on the Impacts on Measurement of the Grain Size of Loess Sediment from Pretreatment. Chin. Sci. Bull. 42, 2535-2538. doi:10.1007/bf02882455

Miao, X., Wang, H., Hanson, P. R., Mason, J. A., and Liu, X. (2016). A New Method to Constrain Soil Development Time Using Both OSL and Radiocarbon Dating. Geoderma 261, 93-100. doi:10.1016/j.geoderma.2015.07.004

Murray, A. S., and Wintle, A. G. (2000). Application of the Single-Aliquot Regenerative-Dose Protocol to the $375^{\circ} \mathrm{C}$ Quartz TL Signal. Radiat. Measurements 32, 579-583. doi:10.1016/S1350-4487(00)00089-5

Nesbitt, H. W., and Young, G. M. (1989). Formation and Diagenesis of Weathering Profiles. J. Geology. 97, 129-147. doi:10.1086/629290

Prescott, J. R., and Hutton, J. T. (1994). Cosmic ray Contributions to Dose Rates for Luminescence and ESR Dating: Large Depths and Long-Term Time Variations. Radiat. Measurements 23, 497-500. doi:10.1016/1350-4487(94)90086-8

Qiang, M., Chen, F., Song, L., Liu, X., Li, M., and Wang, Q. (2013). Late Quaternary Aeolian Activity in Gonghe Basin, Northeastern Qinghai-Tibetan Plateau, China. Quat. Res. 79, 403-412. doi:10.1016/j.yqres.2013.03.003

Qiang, M., Jin, Y., Liu, X., Song, L., Li, H., Li, F., et al. (2016). Late Pleistocene and Holocene Aeolian Sedimentation in Gonghe Basin, Northeastern QinghaiTibetan Plateau: Variability, Processes, and Climatic Implications. Quat. Sci. Rev. 132, 57-73. doi:10.1016/j.quascirev.2015.11.010

Qin, X. G., Yin, Z. Q., Wang, M. H., Zhao, W. J., Mu, Y., and Zhang, L. (2017). Loess Records of the Holocene Climate Change of Gonghe and Guide Basins in the Northeastern Boundary of the Tibet Plateau. Acta Pedologica Sinica 91, 266-286.

Stauch, G., Lai, Z., Lehmkuhl, F., and Schulte, P. (2018). Environmental Changes during the Late Pleistocene and the Holocene in the Gonghe Basin, northeastern Tibetan Plateau. Palaeogeogr. Palaeoclimatol. Palaeoecol. 509, 144-155. doi:10.1016/j.palaeo.2016.12.032

Sun, M., Sun, Y., Wei, H., Hou, G., Xianba, J., Xie, L., et al. (2021). Luminescence Dating of Relics in Ancient Cities Provides Absolute Dates for Understanding Human-Land Relationships in Qinghai Lake Basin, Northeastern Tibetan Plateau. Front. Earth Sci. 9, 701037. doi:10.3389/feart.2021.701037

Sun, Q. F., Cheng, B., and Zhao, L. (2014). Climate and Environment Phase Deviation Recorded by clay Minerals and Pollen since the Late Deglacial in the Gonghe Basin. J. Desert Res. 34, 1237-1247. doi:10.7522/j.issn.1000-694X.2013. 00445

Wang, Y., Guo, F., Ma, L., Yan, Y., Liu, X., and Sun, Y. (2020). Millennial-scale Summer Monsoon Oscillations over the Last $260 \mathrm{Ka}$ Revealed by HighResolution Elemental Results of the Mangshan Loess-Palaeosol Sequence from the southeastern Chinese Loess Plateau. Quat. Int. 552, 164-174. doi:10.1016/j.quaint.2020.05.039

Wei, H. C., E, C. Y., Duan, R. L., Zhang, J., Sun, Y. J., Hou, G. L., et al. (2021). Fungal Spore Record of Pastoralism on the NE Qinghai-Tibetan Plateau since the Middle Holocene. Sci. China Earth Sci. 51, 1907-1922. doi:10.1007/s11430-0209787-4

Wintle, A. G., and Murray, A. S. (2006). A Review of Quartz Optically Stimulated Luminescence Characteristics and Their Relevance in Single-Aliquot Regeneration Dating Protocols. Radiat. Measurements 41, 369-391. doi:10. 1016/j.radmeas.2005.11.001

Xu, S. Y. (1987). Depositional Period and Sedimentary Environment of Gonghe Series in the Qinghai Province, China. Research Group of "Paleogeographical Evolution of the Late Cenozoic in the Northeast Marginal Regions of QinghaiXizang Plateau". J. Lanzhou Univ. (Natural Sciences) 23, 109-119. doi:10.13885/ j.issn.0455-2059.1987.02.019

Yan, D., Wünnemann, B., Zhang, Y., Long, H., Stauch, G., Sun, Q., et al. (2018). Response of lake-catchment Processes to Holocene Climate Variability: Evidences from the NE Tibetan Plateau. Quat. Sci. Rev. 201, 261-279. doi:10.1016/j.quascirev.2018.10.017

Yan, W. T., E, C. Y., Jiang, Y. Y., Sun, Y. J., Lv, S. C., Zhang, J., et al. (2019). Study on the History of Eolian Sand Activities in Gonghe Basin Based on OSL Dating. J. Salt Lake Res. 27, 28-38. doi:10.12119/j.yhyj.201901004

Yang, B., Qin, C., Bräuning, A., Osborn, T. J., Trouet, V., Ljungqvist, F. C., et al. (2021). Long-term Decrease in Asian Monsoon Rainfall and Abrupt Climate Change Events over the Past 6,700 Years. Proc. Natl. Acad. Sci. USA 118, e2102007118. doi:10.1073/pnas.2102007118

Zhang, F. X., Lei, D. T., and Tian, Z. X. (1988). Ancient Graziery in Qinghai. Agr. Archaeol. 02, 358-365. 
Zhang, J., E, C., Wu, C., Sun, Y., Li, P., Shi, Y., et al. (2020). An alpine Meadow Soil Chronology Based on OSL and Radiocarbon Dating, Qinghai Lake, Northeastern Tibetan Plateau. Quat. Int. 562, 35-45. doi:10.1016/j.quaint. 2020.05.044

Zhang, J., E, C. Y., and Zhao, Y. J. (2018). A High-Density Optically Stimulated Luminescence (OSL) Dating at Heima He Loess Section in Qinghai Lake Area. J. Earth Environ. 9, 557-568. doi:10.7515/JEE182048

Zhang, P. X., Zhang, B. Z., and Yang, W. B. (1989). On the Model of post-glacial Palaeoclimatic Fluctuation in Qinghai Lake Region. Quat. Sci. 9, 66-77.

Conflicts of Interest: The authors declare that the research was conducted in the absence of any commercial or financial relationships that could be construed as a potential conflict of interest.
Publisher's Note: All claims expressed in this article are solely those of the authors and do not necessarily represent those of their affiliated organizations, or those of the publisher, the editors and the reviewers. Any product that may be evaluated in this article, or claim that may be made by its manufacturer, is not guaranteed or endorsed by the publisher.

Copyright (c) $2022 \mathrm{Xu}$, E, Shi, Zhang, Sun, Zhang and Zeng. This is an open-access article distributed under the terms of the Creative Commons Attribution License (CC $B Y)$. The use, distribution or reproduction in other forums is permitted, provided the original author(s) and the copyright owner(s) are credited and that the original publication in this journal is cited, in accordance with accepted academic practice. No use, distribution or reproduction is permitted which does not comply with these terms. 